\title{
Cultural Introduction in English Teaching
}

\author{
Shuang Lu \\ College of Foreign Languages, Bohai University, Jinzhou, 121013, China \\ huaruyu@hotmail.com
}

Keywords: English teaching; culture introduction; vocabulary; discourse; grammar; context; reading

\begin{abstract}
Culture is a complicated synthesis, in view of English teaching is concerned, involved in the history of the English-speaking countries, geography, local conditions and customs, traditions, way of life, literature and art, behavior norms and values, etc., each aspect has very rich contents. Language is an integral part of culture, culture of import can stimulate students' interests, meet the requirements of language learning, promote language teaching, has a positive impact on language learning. Only mastered the relevant cultural knowledge, it can use English correctly in intercultural communication. Therefore, cultural introduction is an important content of English teaching. This article from the "reveal cultural connotations of the vocabulary, excavate the cultural information of discourse, blend in the culture of the grammatical perspective, create a real cultural context, and penetrate cultural knowledge in reading" and so on cultural import strategies are proposed.
\end{abstract}

\section{Introduction}

The overall objective of English education is to cultivate students' comprehensive language using ability. Comprehensive language using ability formation based on students' language skills, language knowledge, emotional attitude, learning strategies and cultural awareness, etc. On the basis of overall development linguistic knowledge is the foundation of comprehensive language using ability and language skills, cultural awareness is the assurance of appropriate use of language, emotional attitude is the important factors that affect students' learning and development, learning strategy is to improve the learning efficiency and the development of autonomous learning ability. Can therefore be understood as: English education's goal is to improve students' comprehensive quality, namely, trains the student to have the more proficient language skills, knowledge of language, the learning process of experience, good English communication ability, scientific inquiry learning method and team cooperation consciousness, ready to receive the world excellent cultural consciousness of opening, lasting study enthusiasm, good learning habits and self-confidence to learn English well. The cultural awareness developed through culture teaching. The status of culture teaching in foreign language teaching, as well as the problem of the relationship between language teaching and culture teaching, over the past century is an important topic in the field of foreign language teaching, more and more foreign language education workers realize that linked to learning a foreign language culture should become the important content of foreign language teaching, introduce the culture teaching in foreign language teaching has become the consensus of many scholars and foreign language teachers.

To cultivate the students' communicative competence in language teaching at the same time, must carry out the import of the target language culture, develop the students' ability of social culture, it is by the characteristics of language itself and the relationship between language and culture. Because language is an integral part of culture, only to master the language symbol system, instead of learning the cultural connotation, can appear can speak a foreign language, but pragmatic errors occur frequently. Along with the development of China's foreign open, cross-cultural communication is increasing, due to the differences in communication between different cultures cause misunderstanding to happen from time to tomes, the fact that more and more people realize the importance of "social culture" in English teaching. Cultural import can stimulate students' interest, meet the requirements of language learning, promote language teaching, has a positive impact on language learning. In the imported cultural knowledge, to combine the context of cultural 
background and cultural connotation, often give students with British and American culture, correct is not suitable for the language of the British and American culture. And English learning "in listening, speaking, reading, writing and translating" each link, is inseparable from the cultural background knowledge. Only mastered the relevant cultural knowledge, it can use English correctly in intercultural communication.

\section{Reveal Cultural Connotations of the Vocabulary}

A significant role in language learning, vocabulary, vocabulary teaching is separated from the specific cultural information of vocabulary itself with. In different ethnic groups, as a result of geography, customs, religions and values differences, to express the same rational concept of word, under the unique cultural tradition of their own, will inevitably produce additional concepts of associative meaning in vocabulary itself. The meaning is not necessarily linked with the meaning itself, but in "on the basis of speaker and listening to the cultural knowledge, in a particular context, for the vocabulary of a particular experience, is often a moral". Don't understand the difference of the associative meaning, can't fully accept all one word conveys language information. English vocabulary contains a variety of associative meaning, has the rich cultural connotation, reflects the British and American every aspect of social life. Cultural connotation of words influence English teaching and an important factor of the communication ability of students, vocabulary specific connotation is decided by its cultural environment, and has certain stability, but can vary with the change of peripheral environment [1, 2].

In the interpretation of the English word pronunciation, spelling and collocation relationship between language knowledge at the same time, pay attention to the cultural background, to teach vocabulary students in addition to the general knowledge of vocabulary, also need to know how to use. Specific methods include three aspects: first, start from the origins of words. Behind each term, with a particular period of culture, has the special historical significance. Therefore, in the interpretation of the words, through the origin, to carry out cultural introductory teaching will have twice the result with half the efforts. Second, start from the meanings of words. From different vocabulary in eastern and western nations have different levels of meanings, excavate the bearing cultural information, strengthen students' understanding and memory of vocabulary. Third, start from the emotional color of words. Because of different cultural background, which leads to the words in the aspect of connotation and emotional color differences, teachers can also from the aspects of cultural introductory teaching. Focuses on cultural connotation is different, the lexical three-dimensional, let the students can more easily and master.

\section{Excavate the Cultural Information of Discourse}

Discourse refers to the actual use of language unit, is in the process of a series of continuous communication language sentence or paragraph of language as a whole. It is relative to the discourse teaching in terms of vocabulary and sentence structure as the center of teaching. Discourse can be a dialogue, can also be a monologue. Include written and oral English. Discourse teaching from understanding the content of the whole paper, apply what they have learned language and knowledge and to capture the important clues, to read the article to get an overall impression, then segment (discourse) find out the main idea and important information, the article to carry on the superficial understanding; On this basis, to understand the author's intention and position, to deeply understand the discourse; Then content expressed by the students according to the author, express your views and opinions, to evaluative understanding.

English discourse to deduce structure is given priority to, straightforward; Discourse is given priority to with inductive structure of Chinese and is usually circuitous and implicative. Discourse teaching and cultural import to enrich the students' language structure, expand the students' cultural field of vision, improve students' cross-cultural communication ability plays an important role in [3].Teacher culture teaching should be import and melt in the language teaching, from the viewpoints of language, culture and communication, on the surface of accurate graphic description 
language and culture, from the deep language culture for accurate interpretation and judgment, make the students master English discourse language habits, behavior characteristics and cultural connotation, as well as for the English language entry asked the sensitivity and do as the Romans do consciousness, so as to really master the language [4]. Cultural interpretation of a text, however, is by the specific culture background to interpretation, therefore, as an English teacher, should have more social cultural perspective of language background, it should be strengthened in the process of English teaching discourse culture and guide people to the teaching of discourse analysis. This is also the important content of English teachers in discourse teaching and the direction of the integration of language and culture teaching.

\section{Blend in the Culture of the Grammatical Perspective}

Grammar is a branch of linguistics, the research on usage to use "parts of speech", "the word" tortuous changes or other means, says the relationship each other and the functions and relations in the word in a sentence. Include word formation, configuration rules and this set of rules. Grammar has two meanings, one is, grammar structure law itself, namely grammar; Second, syntactics, is to explore and descriptive grammar structure of science, is a grammatical scholars understanding of objective existence of grammar and instructions. Thus, grammar is the organization of language rules, gives language structure system; Building material language, vocabulary is through grammar and gives meaning to the language content. Grammar as a structural system, it is the structure of language system, voice system and semantic hub of the system. Focus on English grammar teaching purpose is to help students learn English grammar at the core of the project, improve the ability of proper use in the context of English grammar and accuracy to use English, make students have systematic knowledge of English grammar, and be able to use English grammar knowledge to solve the relevant problems in the process of English learning [5].

Show focus on abstract thinking, analytical and logical characteristics, cognitive activity value analysis and detail, attaches great importance to the form. This kind of culture and thinking characteristics embodied in the language that makes up the biggest characteristic of English: hypotaxis, namely the exquisite language structure coordination of external form. English vocabulary has strict morphological changes, the sentence emphasizes the unity of the person, number and case, with associated words show that the grammar relations between the parts of the sentence and the semantic logic [6].Has the characteristics of the dominant and English grammar, language is rigorous, clear, logical; Chinese philosophy emphasizes the unity, pay attention to the harmony between main body and object, so the Chinese culture has a comprehensive, complete and harmonious, symmetry and balance, etc. of personal feelings and got the message, attaches great importance to the psychological time and space and time order. This kind of thinking and cognitive characteristics reflected in the language are formed the "parataxis of Chinese. "Parataxis grammar" is the characteristic of Chinese grammar, structure regularity depend mainly on the embodiment of the semantic association rather than grammatical form. Combinations and, reflected most is the semantic rules rather than grammatical forms, grammatical meaning and logic connection often implied between the lines, so simple and fuzzy language, which resulted in the implication of Chinese grammar.

\section{Create a Real Cultural Context}

The connotations and characteristics of rich diversity, according to that the context can be divided into the internal context and language external context. In language communication, both oral communication and written communication, language is inseparable from the internal context and external language context. Internal context refers to the language context, that is, the collocation of words, the choice of sentence, discourse structure and form inside information, such as sequence of words which, internal cohesion; Associated with verbal communication language external context refers to the social context and cultural context and situational context, including a number of factors: social and cultural background, social and political background, communication on both 
sides of the social psychological factors, social roles and communication on both sides of the encyclopedic knowledge, etc. Context of language use have limited effect, on the understanding of words and use. The same words, in a different context, the expression of meaning may be different, then it will be based on specific context accurate understanding; Context of language understanding has a supplementary role, performance in the deep meaning of language and understood the implication. A sentence to express the may only be simple literal meaning, also may be conferred by the context of a deep meaning, it is also possible that a kind of the implication.

Teachers should best on develop teaching resources, the use of the material as the corpus in life. Life of corpus can provide real context for language learning, stimulate students interest, guides the student according to use the language context. Teachers according to the activity of learning content selected student experience, familiar with the topic or social events as a classroom activity. Authentic language material includes two types: the original discourse that exists in the real life, such as English songs, movies, advertisements, news, instructions, etc.; It can be used for language learning. The latter originates from student's life, is more authenticity of teaching, and thus can resonate, has a psychological truth, specific include: the life experience, teachers should focus on students' life experience and interest, study what is the connection with the current English learning, looking for material life with language learning and use the best combining site; Adaptation of materials, the students are familiar with figures or adapted for language news material, material applied in teaching can receive better teaching effect; Set relative to the real situation, situation according to the needs of teaching, can satisfy the teaching content of video, all kinds of ads and manuals, etc., also can adjust measures to local conditions, all kinds of festivals, such as weather conditions, the classroom and students can become the real situation; Real learning activity design, real situations with real events, real context concern about whether students in English classroom teaching activities in the real situation of feelings, practice and use the language [7-9].Comprehension of knowledge in the situation, learn to use in the situation.

\section{Penetrate Cultural Knowledge in Reading}

Reading teaching plays a very important position in English teaching. Reading classes in English teaching in China has also been a backbone course, in each unit to dialogue on the teaching material arrangement which leads to the topic, study or review about language in daily communication, then read the dialogue with the subject of the same language, training of reading skills and learning grammar and vocabulary, and then to use knowledge. Therefore, reading teaching should not only teach language knowledge, but also to train the ability of cross-cultural communication. Reading is not only the expression of text, cultural factors, contains can if you ignore the existence of cultural knowledge will cause differences in understanding. Reading material contains rich cultural knowledge, is to carry on the culture study, and the contrast of cultural differences important way. Strengthen cultural infiltration, the students' cultural schemata to rich, improved language accuracy and language of the understanding of the comprehensive skills. Teachers want to change the teaching methods, change is given priority to with the basic knowledge of the traditional teaching guiding ideology, Fully understand the necessity of cultural penetration in English reading, specific methods as follows[10, 11]:

(1) Class penetration combined with penetration in class, stimulate students' interest. According to teaching content, teachers prepare the corresponding cultural infiltration materials before class, can take advantage of the multimedia display text, images and video, and other cultural content, stimulates the student to the existing cultural schemata, will study the content and the original knowledge, stimulate students interest in learning as well as activate the inner knowledge reserves. Implied a lot of cultural factors in the reading, the teacher must be good at digging the cultural points, on the basis of reasonable, can use oral narrative way, can also encourage students through the Internet, newspapers, magazines and books, such as look, let every student involved in the culture of learning, mobilize interest in cultural infiltration. At the same time, the teacher according to the cultural content to let the students organize various activities, provide opportunities for language practice and cultural experience, improve the understanding of cultural differences. 
(2) The teaching material of deep mining cultural background, choose the rich cultural background knowledge of reading materials supplementary materials. Although the cultural content is comprehensive, but relatively fast development of society, some topic is too old. Teachers should guide students to understand the latest topics, stimulate interest in learning, and expand the cultural background knowledge. Teaching material as a formal textbook has certain stability, teachers can according to the requirements of teaching choose appropriate supplementary reading materials contain rich cultural content. At the same time, teachers should change the traditional language teaching, reading task is not only the text understanding, on the surface of the deep mining the cultural phenomenon in the teaching material, on the basis of the teaching content to adopt flexible teaching methods and the appropriate extension, add color for classroom teaching, let students enjoy reading at the same time, also experience the inherent cultural charm.

\section{References}

[1] C. C. Jin, "Cultural connotation of vocabulary," Journal of Chaohu College, vol. 7, no. 5, pp. 140-142, 2005.

[2] Y. Zheng, "On the cultural connotation of English vocabulary," Science and technology information, vol. 24, no. 8, pp. 236-237, 2006.

[3] L. Q. Liao, "Cultural Input and Discourse Analysis," Journal of Central South University of Forestry \& Technology(Social Sciences), vol. 3, no. 6, pp. 120-123, 2009.

[4] L. Cheng, "Discourse analysis and the application of discourse culture in English teaching," Sun Yatsen University Forum, vol. 26, no. 3, pp. 157-159, 2006.

[5] Y. F. Xu, "Cultural perspective on the necessity of English grammar teaching," Journal of Taiyuan Urban Vocational College,, vol. 13, no. 5, pp. 133-134, 2011.

[6] Y. Lv, "An Analysis of the Promoting Function of Acculturation in College English Grammar Course," Journal of Xinxiang University(Social Sciences Edition), , vol. 24, no. 4, pp. 191-193, 2010.

[7] W. Gan, "The use of context culture in college English teaching," Journal of Chifeng University(Natural Science Edition), vol. 30, no. 7, pp. 219-220, 2014.

[8] J. Ma, "Cultural introduction in College English Teaching in the context of context theory," Read and Write Periodical, vol. 12, no. 7, pp. 16-16, 2015.

[9] J. J. Xie, "Analysis on the construction of cultural context and College English Classroom Teaching," Journal of Hunan Mass Media Vocational Technical College, vol. 15, no. 2, pp. 112-114, 2015.

[10] R. P. Wang, "Cultural Penetration in English Reading Teaching in High Schools," Master's Degree of Shandong Normal University, 2015.

[11] X. Q. Wang, "Cultural Introduction in College English Reading Course," Journal of Changchun Education Institute, vol. 30, no. 12, pp. 96-97, 2014. 